\title{
A OFICINA DE METODOLOGIA ATIVA E PRODUÇÃO ARTICULADA: DO PROJETO AOS RESULTADOS
}

\author{
DIEGO HENRIQUE DAMASCENO COÊLHO ${ }^{1}$, CAMILA BRAGA \\ CORRÊA ${ }^{3}$.
}

\begin{abstract}
${ }^{1}$ Mestre em Justiça Administrativa - PPGJA (UFF); MBA em Gestão Pública (UCAM); Especialista em Direito e Processo do Trabalho com Habilitação no Magistério Superior (FDDJ); Especialista em Pedagogia e Docência em Educação Profissional e Tecnológica (UCAM). profcoelho@ protonmail.com. ${ }^{2}$ Mestra em Justiça Administrativa - PPGJA (UFF). Professora no Centro Universitário UNIFACIG. camilabragacorrea@gmail.com
\end{abstract}

\section{RESUMO}

O presente artigo tem por escopo principal narrar uma experiência didático-científica, realizada por alunos, então graduandos do $8^{\circ}$ período do curso de Direito do Centro Universitário UNIFACIG e mestrandos do Programa de Pós-Graduação Justiça Administrativa da Faculdade de Direito da Universidade Federal Fluminese (UFF), de agosto a dezembro de 2018, no âmbito da Oficina de Metodologia Ativa e Produção Articulada: Conciliação, Mediação e Arbitragem - OMAPA/CMA. A construção dos saberes apresentados, portanto, estão acostados em método descritivo, contemplando análises qualitativas e quantitativas das amostras de artigos científicos produzidos e o número de autores participantes em observação, ao mesmo tempo em que também desenvolve e relata percepções críticas e analíticas extraídas durante a execução da Oficina de Metodologia Ativa e Produção Articulada, descrevendo contextos, situações e adaptações durante os quatro meses de atividades contínuas das equipes na plataforma de edição virtual de textos utilizada. Ao final deste texto, são apontados os resultados alcançados pelo projeto, demonstrando ser possível integrar iniciativas entre a educação pública e a privada, na expectativa de que seja este um modelo pedagógico real, colaborativo e inspirador - sem medo de errar ou de inovar.

Palavras-chave: Metodologias Ativas; Ensino Superior; Mediação; Conciliação; Arbitragem.

\section{THE ACTIVE METHODOLOGY AND ARTICULATED PRODUCTION WORKSHOP: FROM PROJECT TO RESULTS}

\begin{abstract}
The main purpose of this article is to narrate a didactic-scientific experience, carried out by students, then graduating students of the 8th period of the Law course of (name in full) - UNIFACIG and master students of the Professional Master's Degree Program in Administrative Justice of the Law School of the Fluminense Federal University - UFF,
\end{abstract}


from August to December 2018, inside the Active Methodology and Articulated Production Workshop (Oficina de Metodologia Ativa e Produção Articulada: Conciliação, Mediação e Arbitragem - OMAPA/CMA). The construction of the knowledge presented, therefore, is based on a descriptive method, contemplating qualitative and quantitative analyzes of the samples of scientific articles produced, and the number of authors participating in observation, at the same time. in which he also develops and reports critical and analytical insights extracted during the execution of the Workshop on Active Methodology and Articulated Production, describing contexts, situations and adaptations during the four months of continuous activities of the teams on the virtual text editing platform used. At the end of this text, the results achieved by the project are pointed out, demonstrating that it is possible to integrate initiatives between public and private education, in the hope that this will be a real, collaborative and inspiring pedagogical model - without fear of making mistakes or innovating.

Keywords: Active Methodologies; University Education; Mediation; Conciliation; Arbitration

\section{INTRODUÇÃO}

O protagonismo e o empoderamento buscados pelo incentivo à autonomia de alunos nos contextos de suas jornadas educativas permitem que as metodologias ativas possam ser desenvolvidas de maneira pontual, criativa, compartilhada e atualizada (MORAN, 2015).

Ao contrário das aulas expositivas, em que as informações são transmitidas pelos professores, sendo estas recebidas, construídas e desconstruídas dentro de cada aluno, para então serem transformadas em conhecimento (ANTUNES, 2014). As inovações pedagógicas trazidas pelas metodologias ativas podem aguçar o desejo por assimilar novos saberes, ao estimularem a curiosidade, a liberdade criativa e o afeto, ao passo que respeitam os tempos de aprendizagem, e os conhecimentos dos educandos (FREIRE, 1996).

A superação do modelo instrucional tradicional, com a atenção focada no professor, para suprir as demandas de conteúdos para a formação de educandos, por um modelo com mais compartilhamento de construção de conhecimentos (RIO; SANCHES, 2016) também visa a melhor preparação para o mercado de trabalho, dotando indivíduos de práticas, habilidades e competências suficientemente capazes de desenvolver soluções positivas para a sociedade (FREIRE, 1996). A complementação dos estudos acadêmicos, portanto, pode ultrapassar os limites da sala de aula e dialogar com os desafios pedagógicos a serem explorados e utilizados de forma construtiva (STRECK, 2011), explorando contextos fáticos próximos às realidades de cada indivíduo, na qual tal familiaridade contribua para expandir interpretações, mediante a utilização de novas ferramentas de interação, as quais possibilitam a troca de conhecimentos, informações, opiniões e experiências, ao mesmo tempo em que exercitam os domínios cognitivos da criação. 
Sob tais perspectivas, a migração de modelos pedagógicos estaticamente disciplinares, para a incorporação de modelos de ensino nos quais metodologias ativas são empregadas majoritariamente, ou de maneira complementar, pode representar estranhamento, desconforto e insatisfação (FREIRE, 1996), sobretudo quando discentes não se encontram abertos às novas formas de aquisição de conhecimentos (MORAN, 2015), ou à testagem de possibilidades diversas sobre as suas capacidades de aprendizagem (ANTUNES, 2014). Para a implementação mais suavizada e harmônica de metodologias ativas, portanto, importa que as instituições de ensino possam esclarecer aos alunos ingressantes e às suas famílias quanto aos seus paradigmas de ensino, de forma a compreenderem, por exemplo, as novas configurações de salas de aula e outras infraestruturas, a presença de dois ou mais professores para a mesma disciplina e a usabilidade de avaliações interdisciplinares ou mediante $\mathrm{o}$ desenvolvimento de projetos, com propostas mais colaborativas também com as famílias, os relacionamentos profissionais e as necessidades locais comunitárias.

Outro desafio para a aplicação de metodologias ativas, refere-se à capacitação de professores (RIO; SANCHES, 2016) para conhecerem novas ferramentas didáticas e também adaptarem-se, para aderirem a esta forma de educação mais "viva", abrindo mão do controle total da sua forma de lecionar (FREIRE, 1996), mas sabendo interagir com as demandas trazidas por alunos e proporem soluções inovadoras que dialoguem com os conteúdos programáticos, previstos nas normas de educação e pertinentes ao modelo tradicional pedagógico (e.g. saber realizar aprendizagens baseadas projetos, saber conduzir discussões de casos e debates, saber organizar novas formas de interação em equipes, saber conciliar novas formas de avaliação). Assim, os professores podem passar por mudanças nas suas lógicas de trabalho, migrando do planejamento do ensino, para o planejamento da aprendizagem, seja individual, seja coletiva, mas privilegiando a construção de posturas autônomas (MORAN, 2015), baseadas na abertura de espaços para a discussão de interesses e realidades.

A usabilidade das metodologias ativas, também alcança as falhas de sistemas de ensino, nos quais são reproduzidos indivíduos não habilitados a atuarem de modo coletivamente responsável, assumindo posturas individualistas e pouco cidadãs (STRECK, 2007). Assim, é possível fugir a um modelo no qual é perpetuada a formatação educativa discriminatória, fragmentada e pouco capaz de pavimentar preceitos éticos e reproduzir hábitos saudáveis, coadunados aos propósitos de uma Administração Democrática, com políticas educacionais mais decentes e integradoras, sob as perspectivas públicas e privadas.

Com base em tais informações, conceitos e paradigmas, os desafios à inovação metodológica se contrapõem às formas de aprendizagem sistematizadas e já referendadas, nas quais a repetição de modelos tradicionais pode representar maior simplicidade e segurança na difusão de conteúdos e disciplinas.

Para inovar, portanto, torna-se necessária a análise criteriosa das possibilidades específicas da área de conhecimento na qual as metodologias ativas serão aplicadas, tendo por base a criação e ou a escolha das ferramentas a serem aplicadas na construção 
de todo o processo pedagógico, bem como as molduras normativas aplicadas ao setor de Educação, nas esferas pública e privada, nas quais as formatações mais amplas das metodologias ativas em sala de aula permitem que um mesmo método seja concebido com capacidades plásticas suficientes para se adaptarem a variados contextos disciplinares ou institucionais, dos níveis básicos aos superiores do ensino.

\section{METODOLOGIA APLICADA}

No contexto da aplicação de metodologias ativas, o presente artigo tem por escopo principal narrar uma experiência didático-científica, realizada por alunos, então graduandos do $8^{\circ}$ período do curso de Direito do Centro Universitário UNIFACIG e mestrandos do Programa de Pós-Graduação Justiça Administrativa da Faculdade de Direito da Universidade Federal Fluminense (PPGJA/UFF), de agosto a dezembro de 2018, no âmbito da Oficina de Metodologia Ativa e Produção Articulada: Conciliação, Mediação e Arbitragem - OMAPA/CMA. A construção dos saberes apresentados, portanto, estão acostados em método descritivo (LAMY, 2011), contemplando análises qualitativas e quantitativas das amostras de artigos científicos produzidos e o número de autores participantes em observação, ao mesmo tempo em que também desenvolve e relata percepções críticas e analíticas extraídas durante a execução da Oficina de Metodologia Ativa e Produção Articulada, descrevendo contextos, situações e adaptações ao longo dos quatro meses de atividades contínuas das equipes na plataforma de edição virtual de textos utilizada.

Ao final deste texto, são apontados os resultados alcançados pelo projeto, demonstrando ser possível integrar iniciativas entre a educação pública e a privada, na expectativa de que seja este um modelo pedagógico real, colaborativo e inspirador sem medo de errar ou de inovar.

\section{A REALIZAÇÃO DO PROJETO}

Dentre as práticas, habilidades e competências a serem desenvolvidas em ambiente universitário, a pesquisa representa a base dos conhecimentos científicos e a complementação dos estudos em ambiente acadêmico (LAMY, 2011), voltados para o desenvolvimento da autonomia da aprendizagem (MORAN, 2015) e do aprofundamento em disciplinas e contextos nos quais o educando demonstre maior aptidão, interesse ou afetividade (FREIRE, 1996). Sob tais perspectivas, buscou-se idealizar um projeto aplicando metodologia ativa e a ampliação dos horizontes profissionais, com o estímulo à pesquisa e à integração de experiências na área, de modo que fosse criado um ambiente de troca de informações, conhecimentos e parcerias, com o objetivo principal de praticar técnicas de redação científica.

Assim, a Oficina de Metodologia Ativa e Produção Articulada foi inicialmente proposta, com a idealização de um projeto integrado à disciplina de Conciliação, Mediação e Arbitragem, ministrada com caráter interdisciplinar, no $8^{\circ}$ período do 
segundo semestre de 2018 (2018.2) do curso de Direito do Centro Universitário UNIFACIG, localizado em Manhuaçu/MG, estando presentes o total de 59 alunos, distribuídos em times, de no mínimo dois e no máximo cinco alunos e, contando com a participação e coautoria de sete Especialistas e Mestrandos do Programa de PósGraduação Justiça Administrativa, da Faculdade de Direito da Universidade Federal Fluminense - PPGJA/UFF, distribuídos em trios, para cada time, totalizando um mínimo de cinco e o máximo de oito coautores por grupo, sendo estas pesquisas desenvolvidas entre os meses de agosto a dezembro de 2018. Desse modo, a escolha do título do Projeto está ligada à aplicação da metodologia ativa em pesquisa acadêmica, articulando a realização de pesquisas e redações científicas confeccionadas em parcerias entre graduandos em Direito do UNIFACIG, como instituição de ensino privada, e o mestrandos do PPGJA/UFF, como instituição de ensino pública, lançando mão do ambiente virtual para as interações e desmaterializando as fronteiras das salas de aula.

Portanto, foi possível delimitar uma área de concentração temática específica, considerando os fenômenos ligados ao Direito, como paradigma mediante o qual a Mediação, a Conciliação e Arbitragem podem ser empregadas como ferramentas de resolução adequada de conflitos, sobretudo em contextos do cotidiano dos discentes ou em áreas de pesquisa já pré-definidas para serem aprofundadas posteriormente, nas elaborações de seus respectivos trabalhos de conclusão de curso e dissertações, mas culminando no incentivo à produção de artigos científicos para eventual submissão e publicação em periódicos abrangendo os seguintes conteúdos programáticos: (I) Evolução dos modos de composição de conflitos de interesses; (II) Acesso à justiça no Brasil; (III) Técnicas de Conciliação e Mediação; (IV) Teoria geral da arbitragem; (V) Arbitragem no Direito Brasileiro; (VI) O advogado como negociador de problemas jurídicos; (VII) Arbitragem internacional; (VIII) Lei 9.099/95; (IX) Lei 10.259/2001; e (X) Lei 13.129/2015.

O projeto da Oficina de Metodologia Ativa e Produção Articulada em Mediação, Arbitragem e Conciliação (MAC) teve por escopo principal oportunizar o ingresso dos discentes nas práticas de pesquisas científicas, conhecimentos metodológicos, interpretação de fontes doutrinárias convergentes ou contrastantes, bem como a prática redacional, além da utilização dos mecanismos de pesquisa como atividade universitária indissociável do ensino e da extensão, do ambiente acadêmico como instância de aprendizagem e produção do conhecimento, das técnicas de estudo, coleta e sistematização de informações na Ciência Jurídica, e da estrutura metodológica do planejamento e execução do trabalho científico.

Para complementar e nortear a execução do projeto da Oficina, foram também delineados os seguintes objetivos específicos, a saber:

- Aprofundar a compreensão e a aplicação quantitativa e qualitativa e as bases interdisciplinares e principiológicas em sede de Conciliação, Mediação e Arbitragem.

- Capacitar os discentes para uso produtivo e responsável dos recursos eletrônicos como fonte de pesquisa, incentivo à leitura e produção de textos em equipe; 
- Estimular a utilização do acervo das respectivas Bibliotecas;

- Instrumentalizar a redação científica metodologicamente correta, com ênfase nas normas técnicas de citação como meio de respeito aos direitos autorais;

- Elaborar resenhas, resumos e projetos para as etapas das pesquisas, desenvolvendo práticas, habilidades e competências, como norte para a redação de monografias, artigos científicos e pesquisas avaliativas, utilizados como requisito parcial para promoção semestral;

- Incentivar estudos e leituras de fundamentação teórica;

- Fomentar debates; exposição oral e oficinas; e

- Promover a troca de conhecimentos entre graduandos e mestrandos.

Desse modo, a confecção dos artigos científicos foi subdividida em cinco grandes momentos, a saber: (I) Apresentação do OMAPA/CMA; (II) Escolha temática; (III) Redação; (IV) Correção Parcial; (V) Entrega da versão final; (VI) Avaliação (em duas etapas); (VII) Apresentação e Círculo de Debates; e (VIII) Organização e Publicação.

Inicialmente, foi apresentado aos graduandos e aos mestrandos, o Projeto da Oficina de Metodologia Ativa e Produção Articulada, aprovado pela Coordenação do Curso de Direito, a Coordenação de Metodologias Ativas e a Direção Acadêmica do UNIFACIG, em 28/08/2018. Todavia, a participação dos mestrandos não incorreu em vinculação direta com o Programa de Pós-Graduação Justiça Administrativa (PPGJA/UFF), mas foi realizada mediante aceitação pessoal dos convites para integrar a equipe de desenvolvimento dos artigos científicos, colaborando com suas bagagens de conhecimentos acadêmicos e vivências adquiridas através de práticas profissionais ligadas ao Direito, conferindo maior robustez e maturidade aos assuntos abordados em sede de pesquisa.

A partir das escolhas dos temas, os graduandos iniciaram a organização do projeto, formando times e propondo seus recortes temáticos específicos, a partir da moldura disciplinar ofertada pelo Projeto, para estruturarem os métodos de pesquisa mais adequados a serem empregados (referencial teórico), selecionarem bibliografias básicas, legislações e jurisprudências, bem como efetuarem pesquisas preliminares para localizarem o "estado da arte" e as possibilidades de garantirem ineditismo às proposições, conforme explicado em sala de aula e revisto durante a execução dos projetos.

As bibliografias básicas acerca de Conciliação, Mediação e Arbitragem foram, inclusive, disponibilizadas a todos os integrantes, no corpo do Projeto aprovado da OMAPA/CMA, somente sendo indicadas as obras que compunham o acervo da Biblioteca do UNIFACIG ou que se encontram disponibilizadas em repositórios e bases consultivas de acesso aberto na internet, sendo permitida e estimulada a utilização de outras fontes de científicas do Direito ou de árvores de conhecimento interdisciplinares e correlacionadas com os assuntos em discussão. 
Tão logo os ajustes principais foram resolvidos, passou-se à fase de efetiva redação dos artigos científicos. Nesse momento, foram delineados os tópicos a serem abordados nas seções dos artigos e foram estabelecidos os prazos a serem cumpridos, conforme o cronograma a seguir apresentado:

Figura 1 - Cronograma geral para realização da Oficina

\begin{tabular}{|c|c|c|c|c|c|c|}
\hline Etapas 2018.2 & Setembro & \multicolumn{2}{|l|}{ Outubro } & Novembro & Dezembro & 2020.1 \\
\hline \multicolumn{7}{|l|}{$\begin{array}{l}\text { Entrega dos } \\
\text { Temas e ajustes } \\
\text { metodológicos }\end{array}$} \\
\hline \multicolumn{7}{|l|}{$\begin{array}{l}\text { Pesquisa e } \\
\text { redação do artigo } \\
\text { completo }\end{array}$} \\
\hline $\begin{array}{l}\text { Entrega parcial } \\
\text { para "Correções e } \\
\text { ajustes" }\end{array}$ & & Entrega & $\begin{array}{l}\text { Correção e } \\
\text { devolução }\end{array}$ & & & \\
\hline \multicolumn{7}{|l|}{$\begin{array}{l}\text { Entrega da versão } \\
\text { final - Seminário e } \\
\text { Pontuações. }\end{array}$} \\
\hline Publicação & & & & & & \\
\hline
\end{tabular}

Fonte: Elaboração própria, 2018.

A utilização de um cronograma teve a função didática de nortear o projeto dentro de um marco temporal concatenado ao calendário semestral do UNIFACIG, permitindo que as metas, reuniões e comunicações entre graduandos e mestrandos pudessem ocorrer em tempo adequado, de modo que a versão para revisão, qualificação e ajustes finais pudesse ser entregues em período tempestivo e o mais próximo possível de uma publicação. Para tanto, foi determinado que os arquivos contendo as pesquisas estivessem dentro dos padrões propostos em Normas da Associação Brasileira de Normas Técnicas - ABNT e em conformidade com as orientações de publicação da Revista Pensar Acadêmico, que é editada pelo Centro Universitário UNIFACIG, como forma de estímulo à produção científica por parte dos discentes da própria instituição. 


\subsection{DIÁlogOS SOBRE OS ARTIGOS E A UTILIZAÇÃO DO EDITOR DE TEXTOS ONLINE}

A metodologia ativa também foi aplicada, especificamente em se tratando da produção articulada, com a escolha da plataforma de edição de textos Google Docs, apesar de existirem outras plataformas elegíveis, com funcionalidades bastante similares. Todavia, tal escolha foi justificada por fatores de simplificação prática. Quando debatidas as possíveis plataformas, todos os autores informaram já possuir acesso ao Google Docs ${ }^{1}$, tendo em vista a anterior criação de seus endereços de e-mail junto à plataforma Gmail, para fins pessoais ou como um dos requisitos para o cadastramento individual e cessão de uso e operação de aplicativos próprios ao Sistema operacional Android, o qual foi desenvolvido principalmente pela empresa Google, em consórcio com outros desenvolvedores de softwares, e cujo acesso à conta permite também ao seu titular a utilização das demais franquias de serviços Google, tais como o armazenamento de arquivos em nuvem (Google Drive), edição de textos (Google Docs) e chamadas de vídeo (Google Meets ou HangOuts), sendo tais instrumentos bastante oportunos para a melhoria das interações e o aperfeiçoamento dos textos, com maior velocidade e precisão. A disponibilização dessas ferramentas de acesso gratuito e livre possibilitaram o meio ambiente pelo qual os autores de ambas as instituições puderam conduzir as pesquisas conjuntamente.

Nesse sentido, a proposta trazida pela OMAPA/CMA também visou superar as limitações físicas da sala de aula, bem como do sistema tradicional de ensino, ao mesclar a utilização do ambiente virtual com a troca de informações e saberes, mediante pares, em uma perspectiva democrática, com discussão das temáticas propostas, o compartilhamento de arquivos com conteúdos e a organização de tarefas, metas e responsabilidades, distribuídas de maneira individual e coletiva.

Todavia, a simplificação do método de comunicação entre autores e o desenvolvimento dos textos mediante a utilização de plataforma virtual, não conseguiu atingir a todos. Apesar do estranhamento com a ambientação às ferramentas da plataforma, muitos autores conseguiram se adaptar ao Google Docs, tendo em vista a sua semelhança de utilização com outros programas de edição de textos já conhecidos e

\footnotetext{
${ }^{1}$ Em tempo: Os nomes de softwares, aplicativos e marcas, bem como as suas indicações e descrições, trazidos a comento no presente texto, possuem caráter meramente exemplificativo, de modo que é deixado expresso que todos os Direitos sobre programas e aplicativos que pertençam ou integrem o grupo Google, bem como pertençam, total ou parcialmente, a personalidades de direito privado e empresas parceiras, sócias, subsidiárias, afiliadas e demais empresas detentoras de títulos de propriedade intelectual ou industrial a elas correlacionadas, previstas nas legislações brasileiras e estrangeiras, em contratos, títulos e demais instrumentos jurídicos, são de propriedade exclusiva de seus titulares e devem ser respeitadas e preservadas. As menções contidas nesta obra têm por objetivo prestar uma contrapartida, em forma de agradecimento público, às ferramentas disponibilizadas gratuitamente pela empresa Google (e suas representações) ao público em geral e que, nas ocasiões relatadas no texto, serviram como o ambiente virtual, oportunizando a realização dos textos desenvolvidos durante o projeto da OMAPA/CMA. Nossos sinceros agradecimentos.
} 
amplamente utilizados em ambientes corporativos e acadêmicos, mas especialmente na área do Direito, sobretudo nas atividades essenciais ao exercício da Advocacia.

Todavia, a possibilidade de conexão com a internet, de modo pleno, no caso de alunos residentes em áreas rurais ou em localidades nas quais não há distribuição por parte de provedores de banda larga, foi um dos percalços a serem superados na redação das pesquisas. Muito embora as instituições de ensino ofereçam acesso a computadores conectados à Internet, quatro alunos do UNIFACIG relataram tais dificuldades, majoradas por circunstâncias outras, tais como por não possuírem também disponibilidade de tempo para se deslocarem até a instituição, em virtude de seus compromissos e cargas horárias de trabalho, ou não estar à época disponibilizado transporte público para os trechos de onde residem até locais onde lhes seja facultado o acesso a computadores e à internet, incluindo instituições de ensino público e privado. Desse modo, foi possível extrair o seguinte gráfico:

Figura 2 - Gráfico do percentual total de autores com conexão e sem conexão doméstica de internet.

Fonte: Elaboração própria, 2020.

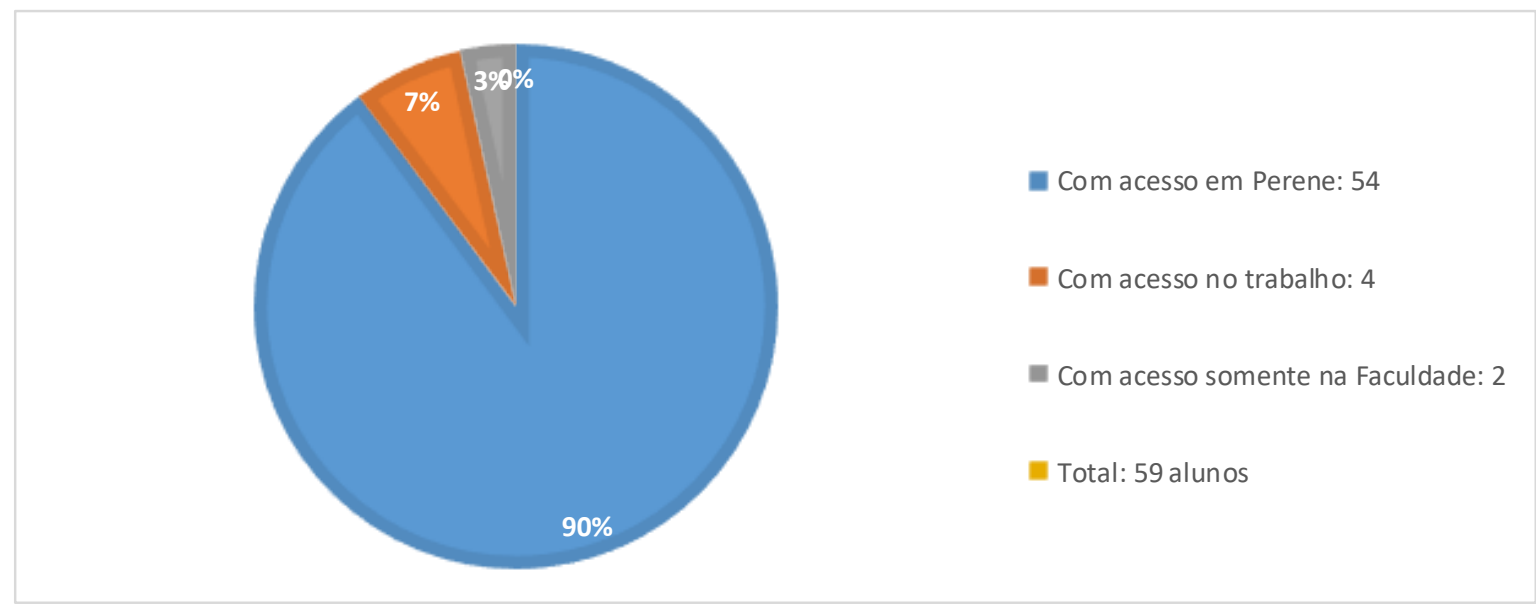

Para superar tais obstáculos, os times nos quais havia autores sem conexão perene com a internet, reorganizaram-se de maneira espontânea e decidiram que atribuiriam atividades específicas para tais membros, como a correção gramatical, semântica e a adequação às normas de formatação propostas, incluindo as referências bibliográficas para que, desse modo, todos os alunos pudessem contribuir sem, contudo, necessitar de acesso à internet. Além disso, uma graduanda sem acesso ao computador durante os finais de semana, optou por redigir uma seção do artigo científico à mão, fazendo consultas em livros físicos, para que outro coautor de seu time transcrevesse para a plataforma de edição de texto os resultados de sua pesquisa. Houve também uma situação em que um graduando desenvolveu o seu texto em um computador e fez uso de um pendrive para juntar ao resto do texto, a sua contribuição. Outro relato trouxe a vivência de que a leitura final e discussão dos ajustes, antes de sua entrega para avaliação, foi realizada em grupo, mas uma aluna participou via telefone fixo, ao 
enfrentar problemas para se conectar à internet e participar das decisões através do chat do Google Docs.

A observação de tais relatos de superação e adaptação permite perceber, também, que os esforços individuais e dos times tornaram possível o amadurecimento das relações, com criatividade, cooperação e compromisso.

\subsection{PROBLEMATIZAÇÃO EM SALA DE AULA: DEBATES E CONFLITOS EM EQUIPE}

A realização do projeto OMAPA/CMA, muito além do tempo de preparação e implantação, demandou um período de tempo relativamente extenso, com a necessidade de reuniões semanais e a participação ativa de todos os integrantes dos times, a fim de que cada projeto pudesse atingir não somente uma pontuação justa nas avaliações, como também possuísse requisitos técnico-científicos suficientes para vislumbrar a possibilidade de submissão e aceite (ainda que com indicações de correção) em periódicos ou livros. Ademais, as várias etapas a serem cumpridas, conforme já elencadas anteriormente, representavam etapas do processo pedagógico de aprofundamento em Metodologias de Pesquisa Científica e Redação Científica, de extrema importância para o amadurecimento dos autores e, portanto, deveriam ser trabalhadas até que todos os integrantes do projeto estivessem bastante familiarizados com as temáticas em Conciliação, Mediação e Arbitragem, seus fundamentos basilares, como também pudessem trazer pontos críticos às discussões em sala, durante o Seminário a ser realizado após a avaliação da versão final de cada artigo científico.

Inicialmente, a proposta compreendia o total de 59 graduandos, permitindo uma subdivisão equânime, em 11 times com cinco integrantes e um time com quatro integrantes, totalizando 12 artigos científicos a serem produzidos. Porém, os conflitos interpessoais e outras variáveis psicossociais e de convívio humano, incidiram na configuração dos grupos, de modo que se avençou permitir a formação de grupos com menor número de integrantes, de modo que ao final do projeto, os graduandos se organizaram em 16 grupos, possuindo entre dois e cinco integrantes, além de três mestrandos em cada grupo.

Durante esta caminhada, conflitos humanos surgiram, mormente relacionados à equidade na distribuição de tarefas e compromisso com os objetivos coletivos. Diante de tais fatos, realizavam-se conversas sob as mais variadas perspectivas, como: para tentar sanar as divergências; buscar identificar as melhores distribuições de tarefas, conforme o perfil de interesse e disponibilidade de cada integrante do grupo; fomentar a pesquisa e o desenvolvimento do trabalho de cada discente na área com que houvesse maior simetria com as disciplinas já cursadas. Enfim, mesmo sendo o desenvolvimento da OMAPA realizado em grupo, tinha o cuidado em serem respeitadas as necessidades individuais de cada integrante de cada um dos grupos.

Nas oportunidades em que foi possível compartilhar as divergências pessoais e de interesses, além das dificuldades tecnológicas ou de elaboração do trabalho, os 
docentes apresentavam soluções criativas, com caráter colaborativo entre integrantes do mesmo grupo e de grupos diferentes, tais medidas encorajaram os discentes a adotarem posturas cada vez mais autônomas e cumpridoras dos requisitos de elaboração de um trabalho científico.

Apesar de todo o engajamento dos envolvidos para que o desenvolvimento do trabalho alcançasse os melhores resultados, em uma situação específica, não se obteve sucesso no restabelecer da união dos integrantes do grupo, o que tornou forçoso a cisão deste grupo.

\subsection{MÉTODOS DE AVALIAÇÃO, PONTUAÇÕES E CORREÇÕES}

Durante a fase de efetivo desenvolvimento das pesquisas, grande parte das correções já eram inseridas, conforme houvesse necessidade. Contando com a experiência mais avançada dos mestrandos, sobretudo no tocante à utilização das metodologias de pesquisa e redação científica, conhecimento mais ampliados de possibilidades de fontes bibliográficas e prática em normatização segundo os padrões da ABNT, os times puderam construir seus textos realizando ajustes de maneira constante.

Entretanto, estava previsto que, ao final da OMAPA/CMA, após a avaliação e a distribuição de pontuações, todos os artigos seriam revistos somente pelos seus autores mestrandos, visando a edição do texto com uma configuração mais harmônica, de modo a garantir que ideias e informações estivessem concatenadas por um "fio condutor", capaz de traduzir, da melhor maneira possível, as percepções obtidas de maneira comunitária.

Aos trabalhos apresentados e efetivamente corrigidos pelos graduandos, conforme orientação dos mestrandos, foi atribuída pontuação até a nota máxima de 15,0 pontos, de um total de 100 pontos, por semestre, para a Disciplina de Conciliação, Mediação e Arbitragem. Conforme já constava previsto no Cronograma do OMAPA/CMA, para fins de avaliação, os trabalhos deveriam ser entregues com o conteúdo finalizado até o dia 30/10/2018, quando seriam distribuídos 9,0 pontos, com base em critérios avaliativos eminentemente técnicos, lastreados em um espelho de correção geral que contemplava, precipuamente, regras de formatação, itens de estrutura textual, semântica e ortográfica, adequação ao tema escolhido, à bibliografia proposta e ao tipo de texto solicitado, bem como a estrutura textual e o emprego de linguagem estritamente científica e a revisão de incidência de plágio, utilizando os softwares Copy Spider e Plagiarism Cheker ${ }^{2}$, sendo ambas as plataformas de uso livre e gratuitamente disponibilizadas na internet.

\footnotetext{
${ }^{2}$ Os nomes de softwares, aplicativos e marcas, bem como as suas indicações e descrições, trazidos a comento no presente texto, possuem caráter meramente exemplificativo, de modo que é deixado expresso que todos os Direitos sobre a propriedade de programas e aplicativos, total ou parcialmente, de personalidades de direito privado e empresas parceiras, sócias, subsidiárias, afiliadas e demais instituições detentoras de títulos de propriedade intelectual ou industrial a elas correlacionadas, previstas nas legislações brasileiras e estrangeiras, em contratos, títulos e demais instrumentos jurídicos, são de propriedade exclusiva de seus titulares e devem ser respeitadas e preservadas. As menções contidas nesta
} 
Contudo, tais notas ainda não seriam divulgadas aos graduandos, pois havia risco de propiciar a perda de estímulo pela participação na Oficina, de modo que, somente durante o Seminário, como última etapa da Oficina, a ser realizada em sala de aula na primeira semana de dezembro de 2018 , as pontuações seriam apresentadas.

$\mathrm{Na}$ continuidade, os artigos deveriam ser corrigidos mais uma vez, de modo que todos os coautores lessem o conteúdo produzido e identificassem falhas ou possibilidades de melhoria, focando apenas na finalização do texto, com o aperfeiçoamento de ideias e da escrita. Nesse ponto, a participação dos mestrandos assumiu especial protagonismo, no sentido de se comprometerem a rematar com o devido esmero todo o texto, ao mesmo tempo em que atuavam junto aos graduandos, no intuito de realizar inserções e exclusões, bem como demais adaptações e avaliações de caráter subjetivo, porém capazes de atribuir maior qualidade ao texto, dinamismo e fluidez à leitura e aprofundamento das discussões.

Após esta última fase de correções, ainda restavam 6,0 pontos a serem distribuídos. Para tanto, a divisão da nota seguiu três contextos, sendo eles: (I) Autoavaliação, atribuindo nota de 0,0 a 2,0 pontos; (II) Avaliação geral do grupo, atribuindo nota de 0,0 a 2,0; e (III) Distribuição de 2,0 pontos de conceito.

$\mathrm{Na}$ autoavaliação, o graduando deveria atribuir uma nota para a sua participação, levando em conta o seu empenho individual e a contribuição oferecida ao trabalho, buscando traduzir suas ações com ética, justiça e honestidade. Na avaliação geral do grupo, cada aluno deveria analisar todos os momentos de construção dos textos, durante a OMAPA/CMA, avaliando o comprometimento coletivo e, na sua visão, a qualidade do artigo entregue.

Depois, foi realizado um cálculo proporcional, para extrair uma média geral para o grupo, ou seja, uma nota única. Como havia times formados por dois, até cinco graduandos, foi estipulado que todas essas notas seriam somadas e do coeficiente obtido, dois pontos seriam subtraídos. Após, o resto ainda seria divido à metade (por 2), conforme o expressa a equação a seguir:

\section{$\frac{[\text { Nota total }(\text { Etapa } 1+\text { Etapa } 2)]-2,0 \text { pontos }}{\text { Número de integrantes do time }}=$ Nota Proporcional do time}

A tabela abaixo exemplifica, também, como as notas puderam ser calculadas e como foi encontrada uma fórmula capaz de garantir paridade a todos, quando da valoração final das atividades, independentemente do numerário de graduandos presentes em cada time. Logo:

obra têm por objetivo prestar uma contrapartida, em forma de agradecimento público, às ferramentas disponibilizadas gratuitamente pelas empresas titulares dos softwares Copy Spyder e Plagiarism Cheker (e suas representações) ao público em geral e que, nas ocasiões relatadas no texto, serviram como o ambiente virtual oportunizador para a checagem dos textos desenvolvidos durante o projeto da OMAPA/CMA. Nossos sinceros agradecimentos. 
Figura 3 - Tabela demonstrativa empregada para o cálculo proporcional das notas na segunda fase avaliativa da OMAPA/CMA.

\begin{tabular}{|l|l|l|l|l|l|}
\hline $\begin{array}{l}\text { Número de } \\
\text { Participantes }\end{array}$ & $\begin{array}{l}\text { Notas } \\
\text { atribuídas na } \\
\text { autoavaliação }\end{array}$ & $\begin{array}{l}\text { Notas } \\
\text { atribuídas } \\
\text { na avaliação } \\
\text { geral }\end{array}$ & $\begin{array}{l}\text { Soma entre } \\
\text { notas }\end{array}$ & $\begin{array}{l}\text { Equação de } \\
\text { divisão } \\
\text { proporcional }\end{array}$ & Resultado \\
\hline $\mathbf{2}$ & $\begin{array}{l}2,0 \text { pontos } \\
2,0 \text { pontos }\end{array}$ & 2,0 pontos & 6,0 & $6-2 / 2$ & 2,0 \\
\hline $\mathbf{3}$ & $\begin{array}{l}2,0 \text { pontos } \\
2,0 \text { pontos } \\
2,0 \text { pontos }\end{array}$ & 2,0 pontos & 8,0 & $8-2 / 3$ & 2,0 \\
\hline $\mathbf{2}$ & $\begin{array}{l}2,0 \text { pontos } \\
2,0 \text { pontos } \\
2,0 \text { pontos } \\
2,0 \text { pontos }\end{array}$ & 2,0 pontos & 10,0 & $10-2 / 4$ & 2,0 \\
\hline $\mathbf{5}$ & $\begin{array}{l}2,0 \text { pontos } \\
2,0 \text { pontos } \\
2,0 \text { pontos } \\
2,0 \text { pontos } \\
2,0 \text { pontos }\end{array}$ & 2,0 pontos & 12,0 & $12-2 / 5$ & 2,0 \\
\hline
\end{tabular}

Fonte: Elaboração própria, 2020.

Já para a Distribuição dos pontos de conceito, a coordenação do Projeto buscou avaliar todas as notas já atribuídas aos times, somá-las e atribuir 2,0 pontos ao trabalho melhor conceituado. A partir de então, utilizou-se um método de distribuição proporcional para os demais times, realizando um cálculo de "regra de três simples", onde:

Figura 4: Tabela explicativa sobre o cálculo das notas de conceito.

\begin{tabular}{|l|l|}
\hline Nota & Conceito \\
\hline 12,5 (maior nota da turma) & 2,0 \\
\hline Y (como nota do grupo) & $\mathrm{X}$ \\
\hline
\end{tabular}

Fonte: Elaboração própria, 2020.

Os cálculos das pontuações distribuídas aos times permitiram a extração do seguinte infográfico: 
Figura 5 - Infográfico com as pontuações obtidas por cada grupo.

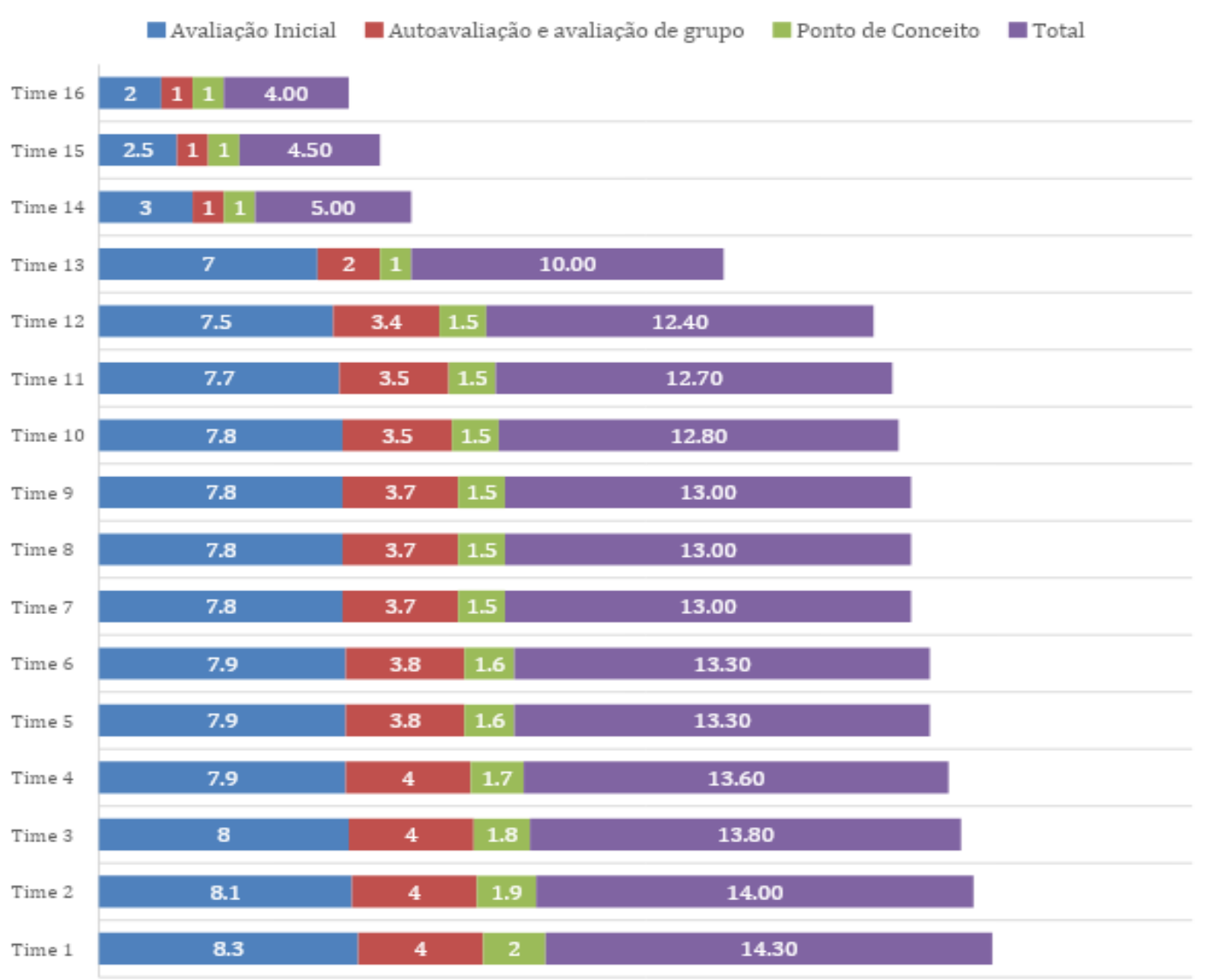

Fonte: Elaboração própria, 2020.

Como é possível depreender do gráfico acima colacionado, ao final das fases de avaliações OMAPA/CMA, as notas obtidas por $82 \%$ dos graduandos foram aproximadas da pontuação máxima estipulada, demonstrando um nível de qualidade bastante acentuado, o que também serve de indicador de segurança, para $o$ desenvolvimento de projetos similares.

Todavia, durante a consecução do projeto OMAPA/CMA, a disciplina de Conciliação, Mediação e Arbitragem, segundo um modelo didático híbrido (metodologia ativa e metodologia de ensino tradicional), também lançou mão de atividades avaliativas de conteúdos (preestabelecidos pela instituição - UNIFACIG, em sede de grade curricular, segundo orientações normativas do Ministério da Educação e Cultura - MEC), nos modelos de prova individual (com perguntas de múltipla escolha e discursivas) e atividades avaliativas complementares para fixação de conteúdo, com listas de perguntas a serem respondidas quinzenalmente, como "trabalho de casa", com o foco voltado para o desenvolvimento das práticas, habilidades e competências dos 
graduandos, para conhecer, manipular e pesquisar textos de Lei, sobretudo com o auxílio de Vade Mecum Jurídico e demais compêndios de Legislações, como ferramentas indissociáveis às operações em Direito, além da apresentação dos Relatórios elaborados pelo Conselho Nacional de Justiça, em especial o Justiça em Números e dos Projetos de Conciliação e Mediação executados por alguns Tribunais.

Nesta perspectiva, alguns times demonstraram um inicial desinteresse pela realização da OMAPA/CMA, culminando em dissidência do projeto, sobretudo mediante as justificativas de que se tratava de uma opção de não fazer, em decorrência da possibilidade de obtenção da pontuação necessária à aprovação na disciplina de Conciliação, Mediação e Arbitragem, mediante os demais mecanismos de distribuição dos 75,00 pontos restantes (retirados os 15,00 pontos atribuídos à OMAPA/CMA), segundo a perspectiva de que o tempo seria melhor aproveitado conhecendo e estudando os conteúdos especificamente trabalhados no campus das provas e atividades de fixação de conteúdo, cujo coeficiente semestral mínimo era de 60,00 pontos em 100,00.

Por se tratar de um projeto de metodologia ativa aplicado graduandos com a participação de mestrandos, em que todos os participantes eram à época indivíduos maiores de idade e plenamente capazes, tais intercorrências são plenamente previsíveis e naturais ao processo de aprendizagem democrática, no qual se buscou, sobretudo, estimular a autodeterminação, a liberdade e o desenvolvimento de ferramentas cuja usabilidade pode ser explorada de maneira bastante ampla e criativa, durante a vida profissional. Neste quesito, amplamente subjetivo, a presente relatoria desta experiência ainda é incapaz de prever ou indicar os coeficientes e impactos futuros, sob desdobramentos positivos ou negativos, às carreiras de cada graduando.

Tal dissidência também impactou a participação de um mestrando, o qual já havia manifestado interesse em integrar os projetos desenvolvidos conjuntamente aos alunos que se desinteressaram pelo OMAPA/CMA. Ainda assim, o mestrando em comento foi convidado a participar de outras temáticas, mas optou por não prosseguir na pesquisa de outros conteúdos, por questões de limitação profissional e incongruências de áreas de pesquisa. Logo, os dados extraídos destas amostras, permitiram a observação das seguintes informações disponibilizadas no gráfico adiante inserto: 
Figura 6 - Integrantes concluintes e dissidentes da OMAPA/CMA

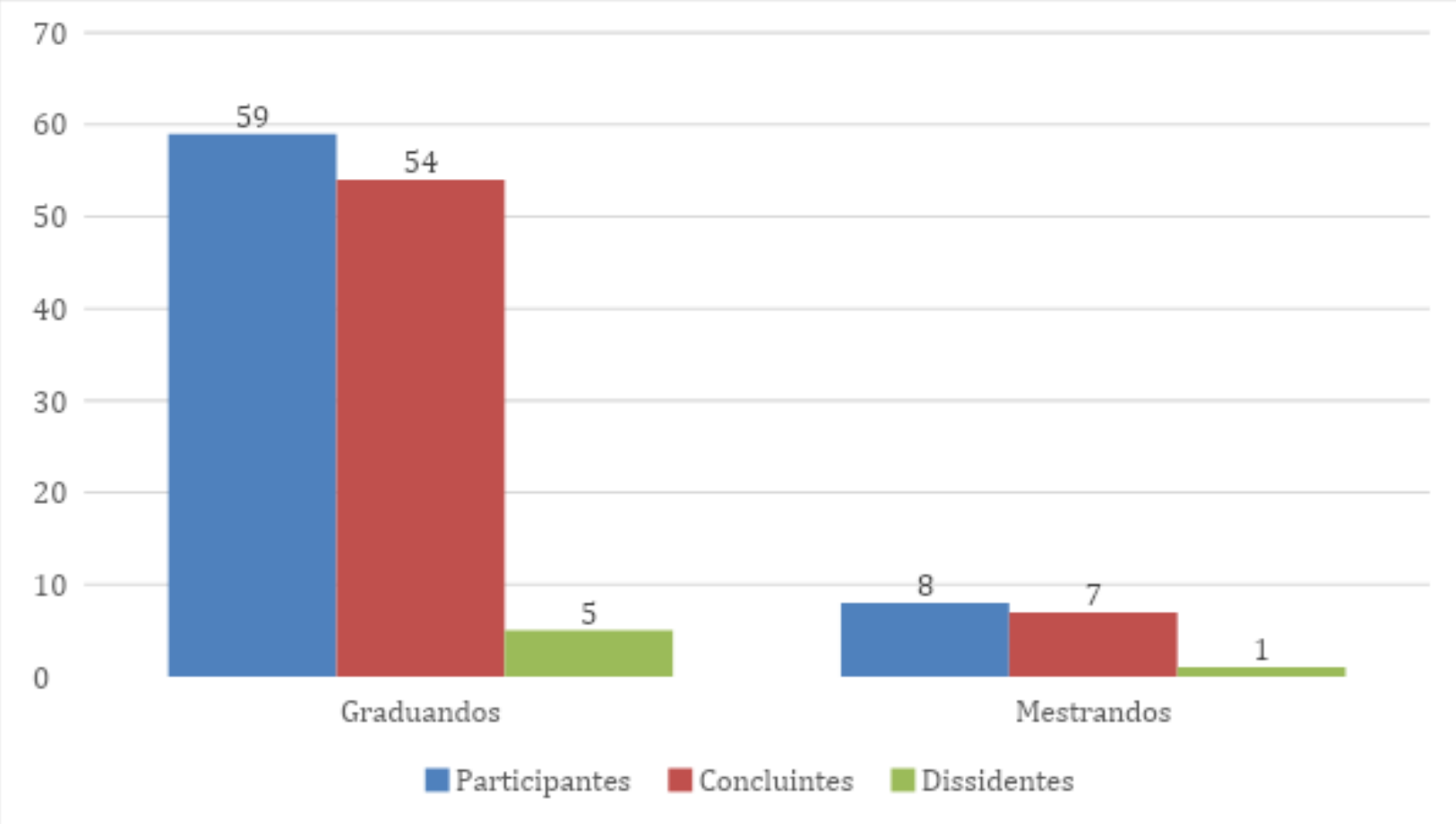

Fonte: Elaboração própria, 2020.

A leitura do gráfico anterior também exprime que a proporcionalidade na escala de abstenção e de participação se deu na proporção de 1 mestrando para 5 alunos (1:5), conforme a formatação do Projeto.

\section{O SEMINÁRIO DA OMAPA/CMA E A PREPARAÇÃO DO LIVRO}

Após a avaliação e a distribuição de pontuações sobre os artigos finalizados, foi possível prosseguir à realização dos debates sobre os resultados encontrados em sede de pesquisa, retornando o foco para a disciplina de Conciliação, Mediação e Arbitragem, mediante a realização de um Seminário em sala de aula.

Para tanto, foi proposto que as apresentações contemplassem dois campos de observação: primeiramente, os graduandos deveriam apresentar aos demais colegas as suas temáticas e demonstrarem o aprofundamento nos temas escolhidos, explicando sua aplicabilidade prática e justificando os motivos de suas escolhas. No segundo momento, os graduandos deveriam expressar as suas observações críticas sobre os novos conhecimentos obtidos em sede de pesquisa, com atenção voltada para as práticas, habilidades e competências exercitadas durante a OMAPA/CMA, sobretudo com apoio e direcionamento dos mestrandos, traçando comparações a respeito de compreensões anteriores e posteriores à realização das pesquisas, no tocante ao aprimoramento de ferramentas aplicadas à Metodologia da Pesquisa e à Redação Científica, bem como as possibilidades de aplicação dos novos saberes às perspectivas profissionais. 
Ao final, foi aberto espaço para discussões acerca dos pontos positivos e negativos, durante os meses de execução do projeto, bem como foram esclarecidas dúvidas ainda remanescentes, sobretudo em relação às possibilidades e maneiras adequadas de submissão de pesquisas científicas em periódicos. A penúltima fase da OMAPA/CMA foi então encerrada.

Em seguida, os organizadores do Projeto passaram à análise criteriosa dos conteúdos produzidos, visando preliminarmente: (I) selecionar quais artigos poderiam ser publicados em periódicos científicos; (II) realizar uma valoração avaliativa quanto ao possível conceito de avaliação atribuído a cada artigo, conforme a classificação dos sistemas avaliativos Qualis Capes de produção científica; e (III) localizar periódicos que aceitariam a publicação de artigos científicos em coautoria entre graduandos e mestrandos. A partir de então, os mestrandos iriam: (IV) adequar a formatação das pesquisas, conforme as orientações para autores e templates dos periódicos selecionados; e (V) realizar a submissão dos artigos, em nome de todo o time.

Durante as primeiras etapas, foram excluídos os trabalhos produzidos pelos graduandos e o mestrando que optaram por não prosseguirem no projeto, pelo fato de que os conteúdos entregues ao final da OMAPA/CMA não possuírem os requisitos técnicos e textuais comumente exigidos para a submissão em um período científico. Já os demais artigos apresentaram níveis de aprovabilidade para publicação bastante grandes, ainda que eventuais ajustes e correções fossem solicitados posteriormente, nos processos de avaliação e revisão. Portanto, foi possível extrair que do conteúdo total produzido, $81 \%$ poderia ser aproveitado, conforme aponta o gráfico a seguir:

Figura 7 - Índice de aproveitamento para o livro (artigos adequados e inadequados).

\section{Coluna 1}

Artigos publicáveis: 13 Artigos não publicáveis: 3 Total: 16 artigos

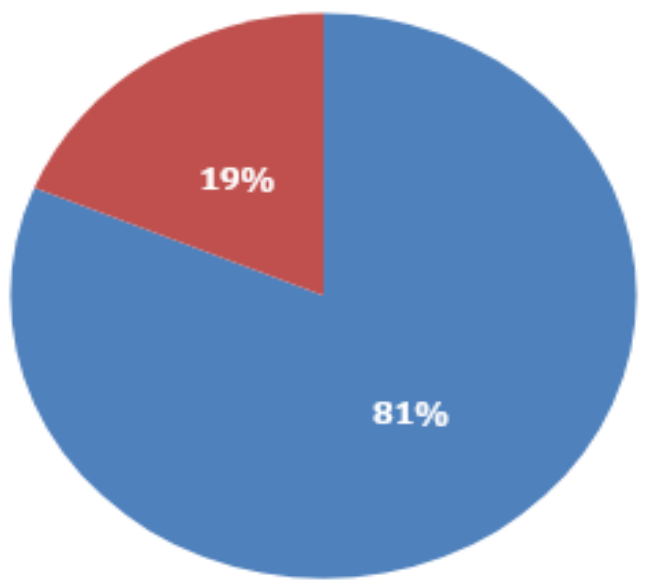

Fonte: Elaboração própria, 2020. 
Todavia, a escolha da destinação dada aos artigos produzidos foi revista pelos organizadores do projeto. Ao longo das pesquisas para definir quais revistas abordavam as temáticas escolhidas pelos graduandos, percebeu-se que os estratos de qualidade conferidos pelas avaliações Qualis Capes poderiam adquirir desdobramentos divergentes às essências integradoras e democráticas nas quais se fundaram o projeto, sob possíveis perspectivas discriminatórias ou comparativas entre todos os participantes, acerca da qualidade final dos trabalhos.

Portanto, formas alternativas de publicação foram mapeadas, de modo que a opção por realizar uma coletânea em formato de livro, com os 13 artigos adequados à publicação, segundo as normas técnico-científicas, foi eleita a modalidade mais equânime e justa de apresentar à comunidade acadêmica os conhecimentos desenvolvidos pelos autores, agora mestres e bacharéis, durante a realização da OMAPA/CMA.

\section{CONCLUSÃO}

O modelo pedagógico pretendido com o presente projeto visa desenvolver profissionais mais preparados para o mercado de trabalho, conscientes de seu processo de aprendizagem, ao longo da vida. Durante a execução do presente projeto, alguns fenômenos também estimularam boas práticas em equipe, com situações de confrontações e debates de opiniões entre colegas ou mediante a aceitação de outros posicionamentos, a colaboração, a divisão de tarefas, a formação de lideranças e interlocuções, a troca de experiências, a superação de desafios para a consecução de um projeto realizado parcialmente online.

Neste sentido, o modelo proposto pela Oficina de Metodologia Ativa e Produção Articulada teve uma concepção voltada para a sua implementação no contexto de uma disciplina de graduação. No caso em observação, tratou-se da disciplina de Conciliação, Mediação e Arbitragem, tão somente pela oportunidade e a coincidência de fatores que permitiram a sua experimentação, tendo em vista a sua capacidade de ser empregada em diversas disciplinas, das mais amplas áreas do saber. Logo, é importante tratar que o modelo propugnado pela OMAPA não se confunde com demais projetos de Iniciação Científica em Universidades, os quais são desenvolvidos e formatados de acordo com estruturas já padronizadas, organizadas e burocráticas, demandando esforços coletivos entre vários agentes, públicos e privados, do setor de Ensino.

O surgimento da OMAPA, como metodologia ativa, refletiu também as solicitações, em sala de aula, de graduandos que demonstravam interesse pela pesquisa científica e desejavam a oferta de um ambiente didático e organizado, no qual tais ferramentas pudessem ser exercitadas de maneira construtiva, de modo que a aprendizagem fosse facilitada, mediante a troca de experiências e saberes, colocando em prática os saberes já absorvidos durante a caminhada universitária, mas podendo exercitá-los de maneira criativa e ampla, a despeito de muitas imposições massificadas um molduras normativas, abarcadas no ensino do Direito. 
Por fim, vale destacar que a temática que serviu de pano de fundo para a construção dos trabalhos da OMAPA/CMA não se limitou ao produto final entregue pelos discentes, como cumprimento parcial para aprovação na disciplina de Conciliação, Mediação e Arbitragem, pois alguns graduandos desenvolveram o Trabalho de Conclusão de Curso sob os vieses das medidas adequadas para a solução do conflito; do acesso à justiça; da judicialização; da ineficácia das medidas até então adotadas pelo sistema judiciário, dentre outras questões, diante do objeto de análise próprio destes trabalhos, como pode ser aferido no Repositório de Trabalhos de Conclusão de Curso de 2019, publicado Portal de Publicação mantido pelo UNIFACIG (quase $20 \%$ dos Trabalhos de Conclusão de Curso, já que dos 47 trabalhos entregues, 09 abordaram as temáticas acima mencionadas). (UNIFACIG, 2019, online).

\section{REFERÊNCIAS}

ANTUNES, Celso. Professores e Professauros: Reflexões Sobre a Aula e Práticas Pedagógicas Diversas. Petrópolis: Vozes, 2014.

FREIRE, Paulo. Pedagogia da autonomia: saberes necessários à prática educativa. Coleção Leitura - São Paulo: Paz e Terra, 1996.

LAMY, Marcelo. Metodologia da pesquisa jurídica: técnicas de investigação, argumentação e redação. Rio de Janeiro: Elsevier, 2011.

MORÁN, José Manuel. Mudando a educação com metodologias ativas. In: Souza, C. A., \& Torres-Morales, O. E. (orgs.). Convergências midiáticas, educação e cidadania: aproximações jovens. Ponta Grossa, PR: UEPG, 2015.

RIO, Josué Justino do; SANCHES, Raquel Cristina Ferraroni. O Ensino Jurídico e a Efetivação do Projeto Pedagógico do Curso de Direito: para uma formação crítica e humanística. São Paulo: Editora Max Limonad, 2016.

STRECK, Lênio Luiz. Ensino Jurídico e Pós-graduação no Brasil: das razões pelas quais o direito não é uma racionalidade instrumental. Revista Novos Estudos Jurídicos, Itajaí, v. 16, n. 1, p. 05-19, jan/abr. 2011. Disponível em: <http://siaiap32.univali.br/seer/index.php/nej/article/view/3266/2048>. Acesso em: 01 jun. 2020.

STRECK, Lênio Luiz. Hermenêutica e Ensino Jurídico em Terrae Brasilis. Revista da Faculdade de Direito UFPR, Curitiba, v. 46, n. 0, p. 25-50, 2007. Disponível em: <http://revistas.ufpr.br/direito/article/view/13495/9508>. Acesso em: 01 jun. 2020. 
UNIFACIG. Revista Pensar Acadêmico. Repositório de trabalhos de conclusão de curso 2019. Disponível em

$<$ http://pensaracademico.facig.edu.br/index.php/repositoriotcc $>$ Acesso em 14 jun. 2020. 